\title{
M. Cohen: A Guide to Special Education Advocacy: What Parents, Clinicians, and Advocates Need to Know
}

\author{
Jessica Kingsley Publishers, Philadelphia, PA, 2009, 302 pp, ISBN 978-1-84310-893-1. \\ $\$ 24.95$ (paper)
}

\author{
Doug Bodin
}

Published online: 23 March 2010

(C) Springer Science+Business Media, LLC 2010

Clinicians who serve children with disabilities are often faced with, and sometimes caught up in, a confusing set of legal regulations that guide the implementation of special education services for these children. Parents and clinicians alike often feel ill-equipped to navigate the multiple steps and reams of paperwork that are often required to assist children who are entering or already involved with the special education system. A guide to Special Education Advocacy, by Matthew Cohen, is designed to assist families and professionals navigate this complex system. Written by an attorney, this book is intended for clinicians, parents, and other advocates of children with disabilities. Clearly written and well organized, the text focuses on the laws and rules that govern special education, while also providing a meaningful context to interpret these legal concepts.

The book includes a brief introduction followed by 13 chapters that cover different special education issues and a final summary chapter. Three appendices follow the chapters. Appendix A lists useful web sites, Appendix B lists commonly used acronyms, and Appendix $\mathrm{C}$ includes several sample letters that parents can use when communicating with schools. Throughout the book, the author includes vignettes to provide a context for relevant legal issues. In addition, the author includes specific advocacy strategies in each chapter to increase the practicality of the text.

The author begins by providing an up to date discussion of the legal protections for children with disabilities. He continues with chapters that focus on rules of eligibility

D. Bodin $(\bowtie)$

Department of Psychology, Nationwide Children's Hospital,

700 Children's Drive, Columbus, OH 43205, USA

e-mail: doug.bodin@ nationwidechildrens.org and the process of initial evaluation and re-evaluation for special education. Chapter 4 is a discussion of the concept of free and appropriate public education and how this concept applies to the IEP process. The following chapters focus on specific special education services, the concept of least restrictive environment, private placement, behavior management, and transition planning. Chapter 10 is a useful discussion of procedural safeguards, mediation, and due process. Chapter 11 is an excellent discussion of the differences between IDEA and Section 504, a distinction that is too often confused by healthcare professionals and parents. In chapter 12, the author provides a psychological and political context for the special education system. Finally, in chapter 13 the author explains how federal laws and regulations are often interpreted differently at federal, state, judicial, and school system levels.

As a psychologist who spends the majority of my time writing evaluation reports for children and their families, I have found A Guide to Special Education Advocacy to be quite useful in my clinical practice. I have recommended the book several times to families during feedback sessions to help them more adequately understand and navigate the special education system. I have also used this text numerous times during supervision sessions with psychology trainees at all levels. Readers of JADD may be disappointed that this book only briefly mentions autism (in the eligibility chapter). However, the author did include a section on specific advocacy strategies for this population. In summary, A Guide to Special Education Advocacy is a well written text that would find a useful place on the bookshelves of both clinicians and parents. I highly recommend it to the readers of JADD. 